\title{
Variation in Cytosine Methylation among Pecan Cultivars at Different Developmental Stages
}

\author{
Zhuang-Zhuang Liu, Tao Chen, Fang-Ren Peng', You-Wang Liang, Peng-Peng Tan, \\ Zheng-Hai Mo, Fan Cao, and Yang-Juan Shang \\ College of Forestry, Nanjing Forestry University, Nanjing 210037, China; Co-Innovation Center for \\ the Sustainable Forestry in Southern China, Nanjing Forestry University, Nanjing 210037, China \\ Rui Zhang \\ State Key Laboratory of Subtropical Silviculture, Zhejiang A\&F University, Hangzhou 311300, China \\ Yong-Rong Li \\ Nanjing Green Universe Pecan Science and Technology Co. Ltd., Nanjing 210007, China
}

\begin{abstract}
Additional INDEX words. Carya illinoinensis, methylation level, methylation pattern, fluorescence-labeled methylationsensitive amplified polymorphism (F-MSAP)

Abstract. Cytosine methylation plays important roles in regulating gene expression and modulating agronomic traits. In this study, the fluorescence-labeled methylation-sensitive amplified polymorphism (F-MSAP) technique was used to study variation in cytosine methylation among seven pecan (Carya illinoinensis) cultivars at four developmental stages. In addition, phenotypic variations in the leaves of these seven cultivars were investigated. Using eight primer sets, 22,796 bands and 950 sites were detected in the pecan cultivars at four stages. Variation in cytosine methylation was observed among the pecan cultivars, with total methylation levels ranging from $51.18 \%$ to $56.58 \%$ and polymorphism rates of $82.29 \%, 81.73 \%, 78.64 \%$, and $79.09 \%$ being recorded at the four stages. Sufficiently accompanying the polymorphism data, significant differences in phenotypic traits were also observed among the pecan cultivars, suggesting that cytosine methylation may be an important factor underlying phenotypic variation. Hypermethylation was the dominant type of methylation among the four types observed, and full methylation occurred at higher levels than did hemimethylation in the pecan genomes. Cluster analysis and principal coordinate analysis (PCoA) identified Dice coefficients ranging from 0.698 to 0.778 , with an average coefficient of 0.735 , and the variance contribution rates of the previous three principal coordinates were $19.6 \%, 19.0 \%$, and $18.2 \%$, respectively. Among the seven pecan cultivars, four groups were clearly classified based on a Dice coefficient of 0.75 and the previous three principal coordinates. Tracing dynamic changes in methylation status across stages revealed that methylation patterns changed at a larger proportion of CCGG sites from the $30 \%$ of final fruit-size (30\%-FFS) stage to the $70 \%$-FFS stage, with general decreases in the total methylation level, the rate of polymorphism, and specific sites being observed in each cultivar. These results demonstrated that the F-MSAP technique is a powerful tool for quantitatively detecting cytosine methylation in pecan genomes and provide a new perspective for studying many important life processes in pecan.
\end{abstract}

As an important epigenetic modification, DNA methylation has become a research focus in the field of molecular biology. This type of modification exists extensively in bacteria, plants, and animals and has both epigenetic and mutagenic effects on various cellular activities, such as differential gene expression, cell differentiation, chromatin inactivation, genomic imprinting, and carcinogenesis (Gonzalgo and Jones, 1997). By contrast to the mutagenic effects of DNA methylation, in which tumor suppressor genes are inactivated through the generation of transition mutations via deamination-driven events, the epigenetic properties of DNA methylation do not involve alterations of the primary DNA sequence, and epigenetic effects appear as altered levels of gene expression. DNA methylation typically occurs via RNA-directed DNA methylation (Movahedi et al., 2015) and is distributed in repeat sequences in coding and

Received for publication 22 Jan. 2018. Accepted for publication 25 Apr. 2018. This study was supported by the SanXin project of Jiangsu province (LYSX[2016]44), the Priority Academic Program Development of Jiangsu Higher Education Institutions (PAPD) and the Doctorate Fellowship Foundation of Nanjing Forestry University.

${ }^{1}$ Corresponding author. E-mail: frpeng@njfu.edu.cn. noncoding regions ( $\mathrm{Lu}$ et al., 2008). Unlike methylation in the mammalian genome, which is restricted to CG sites, DNA methylation in plants predominantly occurs at symmetric CG dinucleotides, symmetric $\mathrm{CHG}$ sites, and asymmetric $\mathrm{CHH}$ sites (where H is A, C, or T) (Bednarek et al., 2017; Finnegan et al., 1998; Zhang et al., 2010). Cytosine methylation of gene promoter regions usually inhibits transcription, but methylation in coding regions (gene body methylation) does not generally affect gene expression (Zhang et al., 2010). Specific DNA methylation occurs in various species, tissues (Lu et al., 2008; Osabe et al., 2014), and ages (Fraga et al., 2002) and plays an important role in adjusting plant growth and development by regulating gene expression. In addition, changes in the methylation status of a plant affect its phenotype and normal development. In Arabidopsis thaliana, decreased methylation causes a number of phenotypic and developmental abnormalities, such as reduced apical dominance, smaller plant size, and altered leaf size and shape (Finnegan et al., 1996). Similarly, phenotypic changes have been observed in transgenic tobacco (Nicotiana tabacum) plants with decreased methylation levels (Nakano et al., 2000). DNA methylation may also respond to external factors to support adaptation and evolution (Fulneček and Kovařík, 2014). In mangrove 
(Laguncularia racemose) plants grown in different environmental conditions (riverside vs. near a salt marsh), the differentiation of epigenetic data were found to be significantly greater than that of genetic data, with significant differences in morphological traits being observed between the two locations, suggesting that epigenetic variation plays an important role in helping individuals cope with different environments (Lira-Medeiros et al., 2010).

Several methods have been developed to study cytosine methylation. However, methods based on bisulfite modification or immunoprecipitation require detailed genomic information for plants. Therefore, in many species for which genomic data are not available, the methylation-sensitive amplified polymorphism (MSAP) method has been used by numerous researchers. MSAP, based on amplified fragment length polymorphism, was introduced by Reyna-López et al. (1997), wherein Mse I was replaced by two isoschizomers (HpaII and MspI) with different methylation sensitivities at CCGG sites. Because MSAP was first applied in rice (Oryza sativa) by Xiong et al. (1999), the technique has been used extensively to study the methylation status of many other plants. Considering the poor safety, low efficiency, and low resolution of the MSAP technique involving polyacrylamide gel electrophoresis, $\mathrm{Xu}$ et al. (2005) introduced a fluorescence labeling system with capillary electrophoresis for MSAP, named F-MSAP, which is safe for researchers and has been demonstrated to show high efficiency and resolution.

As a member of the Carya genus (Juglandaceae), pecan is an economically important and widely cultivated nut crop native to North America (Andersen, 2015; Wood et al., 1990; Zhang et al., 2015b). Many pecan cultivars have been bred and developed in the United States, with rich variations in their leaves, flowers, nuts, and other characteristics. Through more than 100 years of introduction and cultivation, more than 100 pecan cultivars have been preserved in China, including cultivars introduced from America and domestically bred cultivars (Zhang et al., 2015b). However, there are several important problems with the breeding and management of pecan cultivars in China, including cultivar confusion, a narrow genetic basis among domestically bred cultivars, unscientific selection of cultivars for different regions, and slow breeding of fine cultivars, which have markedly restricted the pecan industry in China. Molecular markers can provide numerous polymorphic markers for identifying cultivars and studying genetic diversity, and some markers, such as random amplified polymorphic DNA (RAPD), simple sequence repeats (SSR), and inter simple sequence repeats (ISSR), have been developed in pecan cultivars to elucidate genetic relationships or linkage maps (Conner and Wood, 2001; Grauke et al., 2003; Jia et al., 2011; Kaur et al., 2016; Li et al., 2015). However, some difficulties exist in identifying pecan cultivars with close genetic relationships using these molecular markers. Furthermore, regarding the utility of RAPD in pecan cultivars, a dendrogram based on similarity data showed a relatively weak grouping association among the different cultivars (Conner and Wood, 2001). MSAP has been applied for the identification of cultivars and to reveal methylation variation among cultivars of plants, such as cotton [Gossypium hirsutum (Osabe et al., 2014)], tobacco (Yang et al., 2011), clementine mandarin [Citrus clementina (Fang et al., 2008)], sweet orange [Citrus sinensis (Fang et al., 2010)], and navel orange [C. sinensis (Hong and Deng, 2005)]. Compared with molecular markers,
MSAP markers present higher polymorphism (Fang et al., 2008; Yang et al., 2011), which also suggests the potential involvement of DNA methylation in the regulation of phenotypic traits. To our knowledge, there are no reports on DNA methylation and MSAP in pecan. In addition, with the extensive phenotypic variation among pecan cultivars, the mechanism that regulates phenotypic traits is not clear. Plant growth and development is a complex process with different phenotypic and physiological characteristics among different developmental stages, which are regulated by many factors, including DNA methylation, and little is known about the regulation mechanisms involved in the growth and development of pecan.

In the present study, we analyzed the levels and patterns of cytosine methylation among seven pecan cultivars across four stages using F-MSAP. In addition, we investigated phenotypic variations in the leaves among the cultivars. The main objectives of this study were to analyze the variation of methylation among cultivars, reveal the epigenetic relationships among the pecan cultivars, and trace the changes in methylation as developmental stages proceeded. In addition, we aimed to explore the potential involvement of cytosine methylation in regulating phenotypic traits and developmental processes in pecan.

\section{Materials and Methods}

Plant materials. The pecan orchard in which we conducted sampling is located at Nanjing Green Universe Pecan Science \& Technology Co. in Shanbei Village, Luhe District, Nanjing, Jiangsu Province, China (lat. $32^{\circ} 19^{\prime} 59.48^{\prime \prime} \mathrm{N}$, long. $118^{\circ} 52^{\prime} 22.37^{\prime \prime} \mathrm{E}, 170 \mathrm{~m}$ altitude). The Luhe District has a hot, humid, subtropical climate, with an annual average temperature of $15.1^{\circ} \mathrm{C}$ and rainfall of $1004.4 \mathrm{~mm}$. The average temperatures in July and January are 27.6 and $1.7^{\circ} \mathrm{C}$, respectively. Maximum precipitation occurs in July, with rainfall of $190.9 \mathrm{~mm}$, whereas the minimum rainfall occurs in December, at $22.4 \mathrm{~mm}$. There are $239 \mathrm{~d}$ without frost in this district (Zhang et al., 2015c). The soil is a loam with $\mathrm{pH}$ ranging from 6.5 to 7.5 .

Seven cultivars were selected for this study. Among the seven cultivars, six were introduced from the United States, including Pawnee, Mahan, Stuart, Kanza, Shawnee, and Caddo, whereas Jinhua was selected and bred in China. Three 5-yearold trees (grafted on 5-year-old rootstocks) of each cultivar were selected and marked for the collection of leaf samples. For DNA extraction, three leaflets were harvested from every marked tree on 25 Apr., 5 July, 1 Sept., and 28 Sept. 2016, and all of the leaflets were obtained from compound leaves with an exterior south-facing canopy position $\approx 2-3 \mathrm{~m}$ from the ground (for each compound leaf, only one leaflet was collected from the two to four leaflets from the basal portion of the compound leaf). For the investigation of phenotypic traits, samples of the same type were collected on 5 July. The collected samples were rapidly transported to the laboratory in an ice box. The samples intended for DNA extraction were frozen at $-70{ }^{\circ} \mathrm{C}$, whereas those intended for phenotypic trait analysis were processed immediately. When the leaf samples were collected in every period, their phenological characteristics were observed and recorded.

INVESTIGATION OF PHENOTYPIC TRAITS. Leaflet area (square centimeters), length (centimeters), width (centimeters), and perimeter (centimeters) were measured with a laser area meter (CI-203; CID Bio-Science, Camas, WA), and a protractor was 
used to measure the basic angle (degrees) and apex angle (degrees) of these leaf samples. The leaflet basic angle and leaflet apex angle are the maximum angles of the leaflet base and leaflet tip, respectively. Fresh weights (grams) were determined on an analytical balance $(220 \pm 0.0001 \mathrm{~g}$; Sartorius, Gottingen, Germany). These leaf samples were dried at $60^{\circ} \mathrm{C}$ in an oven (BINDER, Tuttlingen, Germany) until leaflet weight did not change, and the dry weights (grams) were then determined. The water content (percent) was calculated according to the following formula: (fresh weight-dry weight) $\times 100 /$ fresh weight.

DNA EXTRACTION. The procedure of genomic DNA extraction performed in this experiment was developed based on the cetyl trimethylammonium bromide (CTAB) method (Sambrook and Russell, 2001). Briefly, for each cultivar, $1 \mathrm{~g}$ of a mixed leaf sample was quickly ground in liquid nitrogen and was then removed and placed in a $2-\mathrm{mL}$ centrifuge tube. Next, 3-5 $\mathrm{mL}$ of preheated CTAB extraction solution was added, and the mixture was incubated at $65^{\circ} \mathrm{C}$ for $30-60 \mathrm{~min}$ with slight inversion every $10 \mathrm{~min}$. The supernatant was then collected via centrifugation $\left(11,000 g_{\mathrm{n}}, 5 \mathrm{~min}\right)$ and mixed with an equal volume of 1 phenol: 1 chloroform $(\mathrm{v} / \mathrm{v})$. Following centrifugation at $11,000 g_{\mathrm{n}}$ for $10 \mathrm{~min}$, the supernatant was transferred to a fresh tube. Then, an equal volume of chloroform was added, followed by centrifugation at $11,000 g_{\mathrm{n}}$ for $10 \mathrm{~min}$. The supernatant was subsequently collected, and the steps beginning at phenol/chloroform addition were then repeated. The obtained supernatant was mixed with isopropanol at twothirds the volume of the supernatant. This mixture was incubated at room temperature for $15 \mathrm{~min}$ and then centrifuged at $11,000 g_{\mathrm{n}}$ for $6 \mathrm{~min}$. The supernatant was discarded, and the remaining precipitant was washed with $70 \%$ ethanol. The mixture was centrifuged at $11,000 g_{\mathrm{n}}$ for $2 \mathrm{~min}$. The remaining precipitant was repeatedly washed with $70 \%$ ethanol and then dissolved in Tris-EDTA buffer solution (TE buffer).

F-MSAP PROCEDURE. The F-MSAP procedure involves DNA digestion, ligation, preselective amplification, selective amplification, and detection via capillary electrophoresis. A DNA sample was divided into two groups; one group was digested with EcoRI/HpaII and the other with EcoRI/MspI at $37^{\circ} \mathrm{C}$ overnight. Both digestion reactions were performed in a volume of $20 \mu \mathrm{L}$ that included $400 \mathrm{ng}$ of DNA, $8 \mathrm{U}$ of EcoRI [New England Biolabs (NEB), Ipswich, MA], $8 \mathrm{U}$ of HpaII
(NEB) or MspI (NEB), $2 \mu \mathrm{L}$ of $10 \times$ buffer, and double-distilled $\mathrm{H}_{2} \mathrm{O}\left(\mathrm{dd}_{2} \mathrm{O}\right)$. The ligation reaction was performed in a volume of $40 \mu \mathrm{L}$, including $20 \mu \mathrm{L}$ of the digestion products, 10 Weiss units of T4 DNA ligase (NEB), $0.8 \mu \mathrm{L}$ of an EcoRI adaptor $(20 \mu \mathrm{M}$, mixture of adaptor 1 and adaptor 2$), 0.8 \mu \mathrm{L}$ of an HpaII/MspI adaptor $(20 \mu \mathrm{M}$, mixture of adaptor 1 and adaptor 2 of HpaII/MspI), $4 \mu \mathrm{L}$ of $10 \times \mathrm{T} 4$ buffer, and $\mathrm{dd}_{2} \mathrm{O}$. The ligation mixture was incubated at $16{ }^{\circ} \mathrm{C}$ overnight. The adaptors and primers used in the F-MSAP procedure are listed in Table 1. Preselective amplification was performed in a volume of $20 \mu \mathrm{L}$, containing $2 \mu \mathrm{L}$ of the ligation products, $1 \mathrm{U}$ of Taq polymerase (Takara, Kusatsu, Japan), $0.5 \mu \mathrm{L}$ of the E00 primer $(10 \mu \mathrm{M})$, $0.5 \mu \mathrm{L}$ of the M00 primer $(10 \mu \mathrm{M}), 0.4 \mu \mathrm{L}$ of dNTPs $(10 \mathrm{~mm})$, $2 \mu \mathrm{L}$ of $10 \times$ buffer $\left(25 \mathrm{mM} \mathrm{Mg}^{2+}\right)$, and $\mathrm{ddH}_{2} \mathrm{O}$. The reaction conditions were as follows: 26 cycles of $94{ }^{\circ} \mathrm{C}$ for $30 \mathrm{~s}, 56^{\circ} \mathrm{C}$ for $1 \mathrm{~min}$, and $72{ }^{\circ} \mathrm{C}$ for $1 \mathrm{~min}$, followed by $72{ }^{\circ} \mathrm{C}$ for $10 \mathrm{~min}$. The preamplified products were diluted 20 times by volume with $\mathrm{ddH}_{2} \mathrm{O}$ for the selective amplification. The selective amplification reaction system was the same as that used for preselective amplification except the ligation products were replaced with the diluted preamplified products, and the fluorescence label 5-carboxyfluorescein (5' FAM) was added to the E primers. The selective amplification conditions were as follows: 13 cycles of $94^{\circ} \mathrm{C}$ for $30 \mathrm{~s}, 65^{\circ} \mathrm{C}$ for $30 \mathrm{~s}$ reduced by $0.7^{\circ} \mathrm{C}$ per cycle, and $72{ }^{\circ} \mathrm{C}$ for $1 \mathrm{~min}$, followed by 23 cycles of $94^{\circ} \mathrm{C}$ for $30 \mathrm{~s}$, $56^{\circ} \mathrm{C}$ for $30 \mathrm{~s}$, and $72^{\circ} \mathrm{C}$ for $1 \mathrm{~min}$, with a final extension at $72^{\circ} \mathrm{C}$ for $10 \mathrm{~min}$. The selective amplification product was diluted 10 times by volume with $\mathrm{ddH}_{2} \mathrm{O}$ for the subsequent procedure. Briefly, $1 \mu \mathrm{L}$ of the selective amplification product was added to a mixture $(9 \mu \mathrm{L})$ of 100 formamide: 1 LIZ500 DNA standard (v/v) for capillary electrophoresis on an auto sequencer (ABI 3730XL; Thermo Fisher Scientific, Waltham, MA).

DATA STATISTICS AND ANALYSIS. In the statistical analysis of the phenotypic indices, nine leaf samples from each cultivar were regarded as nine replicates. One-way analysis of variance (ANOVA) and Duncan's multiple range test were conducted using SPSS Statistics (version 22; IBM Corp., Armonk, NY). The mean $(\bar{X})$, SD $(\delta)$, and $\mathrm{CV}$ (percent) of each phenotypic index were calculated using the following formulas: $\bar{X}=\sum x_{i} / n, \delta=$ $\sqrt{\sum\left(x_{i}-\bar{x}\right)^{2} /(n-1)}, \mathrm{cv}($ percent $)=100 \times \delta / \bar{x}$. For electropherograms based on the.fsa data obtained with the auto sequencer, GeneMarker (version 2.2.0; SoftGenetics, State College, PA) was used to analyze the peak diagrams. The GS500

Table 1. Sequences of the adaptors and primers used in fluorescence-labeled methylation-sensitive amplified polymorphism (F-MSAP). The F-MSAP technique based on the traditional methylation-sensitive amplified polymorphism technique was used in this study to detect the cytosine methylation level and patterns among seven pecan cultivars.

\begin{tabular}{lll}
\hline & \multicolumn{1}{c}{ EcoRI $\left(5^{\prime}-3^{\prime}\right)$} & HpaII/MspI $\left(5^{\prime}-3^{\prime}\right)$ \\
\hline Adaptor $1^{z}$ & CTCGTAGACTGCGTACC & GACGATGAGTCCTGAG \\
Adaptor 2 & AATTGGTACGCAGTCTAC & CGCTCAGGACTCAT \\
Preselective amplification primers & GACTGCGTACCAATTC (E00) & GATGAGTCCTGAGCGG (H/M00) \\
Selective amplification primers & E00-AAC (E1) & H/M00-AGC (H/M1) \\
& E00-ACC (E2) & H/M00-AGT (H/M2) \\
& E00-AGC (E3) & H/M00-CAC (H/M3)
\end{tabular}

Primer sets

E1-H/M1, E2-H/M3, E3-H/M1, E3-H/M3

E4-H/M3, E5- H/M2, E5-H/M3, E6-H/M4

${ }^{\mathrm{z}} \mathrm{A}$ mixture of adaptor 1 and adaptor 2 for EcoRI and HpaII/MspI was used in this study. 
standard and uniform panels were used to align the electropherograms, and a matrix $(0,1)$ was produced with the software, where " 1 " reflects the existence of an amplified fragment and " 0 " represents no product. Four types of bands were detected, as shown in Table 2, representing different methylation patterns. Methylation levels were calculated according to the following formulas: hemimethylation level = type II bands/total bands; full methylation level = type III/total bands; hypermethylation level = type IV/total bands; total methylation level = (type II + type III + type IV)/total bands (in the formulas, "total bands" indicates the sum of the four band types).

Type IV $(0,0)$ was confirmed as hypermethylation at the site when a sample from the same cultivar at any of the other three stages showed the presence of a fragment (i.e., one type of type I, type II, and type III appeared) at the site; otherwise, it was ignored. In this study, polymorphic sites were defined as the sites with different methylation patterns among the cultivars. Among the polymorphic sites, we also counted the specific sites at which the methylation pattern of a cultivar was different from that of the other six cultivars, whereas the methylation patterns of the other six cultivars were the same. We ignored and did not count sites that could not be definitively confirmed as polymorphic (or specific) sites because of uncertainty in type IV $(0,0)$ status. SigmaPlot software (version 12.5; Systat Software, San Jose, CA) was used to draw radar and bar graphs.

The methylation status of type II, type III, or type IV (hypermethylation) was recorded as " 1 " and that of type I was recorded as " 0 ." An uncertain status was scored as missing data and was recorded as "2." NTSYS software (version 2.10e; Applied Biostatistics, New York, NY) was used to conduct cluster analysis and PCoA with the newly obtained matrix. Pairwise similarity was first obtained by calculating the Dice coefficient using the "similarity of qualitative data (SimQual)" command. Based on the pairwise similarity, the unweighted pair-group method with arithmetic mean was used to construct the dendrogram with the "Sequential, Agglomerative, Hierarchical and Nested Clustering Methods" command. In PCoA, the pairwise similarity had to be transformed into a new matrix file by executing the "Dcenter" command. Thereafter, the "Eigen" command in the "Ordination" module was executed, and two- and three-dimensional diagrams were produced according to the previous two and three principal coordinates, respectively.

Table 2. Differences in HpaII and MspI sensitivity for methylation status and different methylation types (Zhao et al., 2015). The isoschizomer of HpaII is inactive when one or both cytosines are fully methylated but can digest the hemimethylated sequence, whereas MspI is inactive if the external cytosine is fully or hemimethylated. The results of HpaII/EcoRI and MspI/EcoRI digestion are used to reflect the methylation status.

\begin{tabular}{|c|c|c|c|c|}
\hline & HpaII/EcoRI & MspI/EcoRI & Methylation status ${ }^{z}$ & Methylation type \\
\hline $\mathrm{I}$ & Active $(1)^{\mathrm{y}}$ & Active (1) & $\begin{array}{l}\text { CCGG } \\
\text { GGCC }\end{array}$ & Unmethylated \\
\hline II & Active (1) & Inactive $(0)$ & $\begin{array}{c}{ }^{\mathbf{m}} \mathbf{C C G G} \text { or }{ }^{\mathbf{m}} \mathbf{C}^{\mathbf{m}} \mathbf{C G G} \\
\text { GGCC } \quad \text { GGCC }\end{array}$ & Hemimethylation \\
\hline III & Inactive $/ 0$ & Active (1) & $\begin{array}{l}\mathrm{C}^{\mathbf{m}} \mathbf{C G G} \\
\mathrm{GGC}^{\mathbf{m}} \mathrm{C}\end{array}$ & Full methylation \\
\hline IV & Inactive $(0)$ & Inactive $(0)$ & $\begin{array}{l}{ }^{\mathbf{m}} \mathbf{C}^{\mathbf{m}} \mathbf{C G G} \\
\mathrm{GGC}^{\mathbf{m}} \mathbf{C}^{\mathbf{m}} \text { or no } \mathrm{CCGG}\end{array}$ & $\begin{array}{l}\text { Hypermethylation or } \\
\text { no CCGG sequences }\end{array}$ \\
\hline
\end{tabular}

\footnotetext{
${ }^{\mathrm{z}}$ The bold values represent the methylation in the cytosines.

${ }^{\mathrm{y}}$ Sequences of CCGG can be digested by two enzymes (EcoRI and HpaII, or EcoRI and MspI), which is recorded as "Active (1)"; otherwise, it is recorded as "Inactive (0)".
}

\section{Results}

Phenotypic Variation in the leaves of pecan Cultivars AND PHENOLOGICAL CHARACTERISTICS OF FOUR DEVELOPMENTAL STAGES. Leaf phenotypic variation commonly occurred among the pecan cultivars, with $\mathrm{CV}$ ranging from $3.33 \%$ to $12.94 \%$. ANOVA showed that leaflet width, area, droop angle, tilt angle, weight, dry weight, and water content significantly differed $(P<0.05)$, whereas leaflet length and perimeter were not significantly different among the cultivars. Among the seven pecan cultivars, Kanza presented the smallest values for almost all of the phenotypic indices, except for droop angle, tilt angle, and water content (Table 3).

Observation of the phenology at four developmental stages revealed that buds had developed into leaves and flowers were developing in late April; the fruit were in the rapid growth stage in early July; the leaves almost reached full maturity and the kernels nearly filled the nuts in early September; and vegetative growth slowed, the size of fruit was determined and fruit were close to maturity in late September. According to the Biologische Bundesanstalt, Bundessortenamt und Chemische Industrie le for pecan (Han et al., 2018), late April, early July, early September, and late September corresponded to the stages of inflorescence emergence (IE), 30\%-FFS, 70\%-FFS, and fruit maturity (FM), respectively.

DNA METHYLATION LEVELS IN VARIOUS PECAN CULTIVARS. A 作 950 sites were amplified with eight primer sets. Most of 列 $500 \mathrm{bp}$. A total of 22,796 bands were amplified from the (he seven cultivars at four stages, with 3312,3264 Pawnee, Mahan, Stuart, Kanza, Shawnee, Caddo, and Jinhua, respectively (Table 4). The total methylation levels ranged from $51.18 \%$ to $56.58 \%$, with hemimethylation levels ranging from $15.39 \%$ to $18.48 \%$, full methylation levels ranging from $15.39 \%$ to $18.48 \%$, and hypermethylation levels ranging from $20.88 \%$ to $24.37 \%$ among the seven cultivars. Furthermore, hypermethylation levels were the highest among the three methylation types, and full methylation levels were higher than those of hemimethylation in each of the cultivars.

Generally, the levels of hemi- and full methylation substantially decreased from the $30 \%$-FFS to $70 \%$-FFS stages among the pecan cultivars, whereas relatively small differences were observed in these levels between the IE and 30\%-FFS stages and between the $70 \%$-FFS and FM stages (shown in Fig. 1). However, at the FM stage, the levels of full methylation increased by $63.16 \%$ and $37.14 \%$ in 'Pawnee' and 'Stuart', respectively, compared with those at the $70 \%$ FFS stage. Hypermethylation levels similar to the levels of hemi- and full methylation were observed between the IE and 30\%-FFS stages and between the $70 \%$-FFS and FM stages in the pecan cultivars. Nevertheless, hypermethylation levels obviously increased at the $70 \%$ FFS stage, showing the reverse trend of hemi- and full methylation levels. Specifically, for 'Caddo', 
Table 3. Phenotypic variation in the leaves from 5 July among the seven pecan cultivars.

\begin{tabular}{|c|c|c|c|c|c|c|c|c|}
\hline \multirow{2}{*}{$\begin{array}{l}\text { Phenotypic } \\
\text { Index }\end{array}$} & \multicolumn{7}{|c|}{ Mean \pm SD } & \multirow[b]{2}{*}{$\mathrm{CV}(\%)^{\mathrm{z}}$} \\
\hline & Pawnee & Mahan & Stuart & Kanza & Shawnee & Caddo & Jinhua & \\
\hline Length $(\mathrm{cm})$ & $10.40 \pm 1.00 \mathrm{a}^{\mathrm{y}}$ & $10.19 \pm 1.52 \mathrm{a}$ & $10.37 \pm 1.90 \mathrm{a}$ & $9.65 \pm 1.79 \mathrm{a}$ & $9.90 \pm 1.11 \mathrm{a}$ & $11.80 \pm 0.49 \mathrm{a}$ & $10.46 \pm 1.79 \mathrm{a}$ & 6.61 \\
\hline Width (cm) & $3.93 \pm 0.19 \mathrm{a}$ & $4.14 \pm 0.52 \mathrm{a}$ & $4.14 \pm 0.52 \mathrm{a}$ & $3.51 \pm 0.52 \mathrm{~b}$ & $3.99 \pm 0.43 \mathrm{a}$ & $4.09 \pm 0.42 \mathrm{a}$ & $4.35 \pm 0.32 \mathrm{a}$ & 6.54 \\
\hline Perimeter $(\mathrm{cm})$ & $22.58 \pm 1.69 \mathrm{a}$ & $23.10 \pm 1.85 \mathrm{a}$ & $24.06 \pm 2.75 \mathrm{a}$ & $21.58 \pm 2.51 \mathrm{a}$ & $22.46 \pm 2.62 \mathrm{a}$ & $24.61 \pm 1.10 \mathrm{a}$ & $23.05 \pm 0.60 \mathrm{a}$ & 4.40 \\
\hline Basic angle $\left({ }^{\circ}\right)$ & $83.33 \pm 9.92 \mathrm{c}$ & $98.89 \pm 6.57 \mathrm{a}$ & $94.89 \pm 7.13 \mathrm{ab}$ & $88.33 \pm 13.22 \mathrm{bc}$ & $93.11 \pm 4.94 \mathrm{ab}$ & $95.67 \pm 5.81 \mathrm{ab}$ & $96.22 \pm 5.83 \mathrm{ab}$ & 5.74 \\
\hline Apex angle $\left(^{\circ}\right)$ & $31.33 \pm 5.00 \mathrm{ab}$ & $30.89 \pm 7.61 \mathrm{ab}$ & $28.22 \pm 5.26 \mathrm{ab}$ & $25.67 \pm 5.81 \mathrm{~b}$ & $25.56 \pm 4.07 \mathrm{~b}$ & $26.00 \pm 1.73 \mathrm{~b}$ & $32.89 \pm 7.66 \mathrm{a}$ & 10.65 \\
\hline Dry wt (g) & $0.19 \pm 0.03 \mathrm{a}$ & $0.20 \pm 0.01 \mathrm{a}$ & $0.21 \pm 0.03 \mathrm{a}$ & $0.14 \pm 0.03 \mathrm{~b}$ & $0.19 \pm 0.03 \mathrm{a}$ & $0.19 \pm 0.03 \mathrm{a}$ & $0.18 \pm 0.02 \mathrm{a}$ & 12.94 \\
\hline $\begin{array}{l}\text { Water } \\
\quad \text { content }(\%)\end{array}$ & $61.49 \pm 1.53 \mathrm{a}$ & $61.24 \pm 3.36 \mathrm{a}$ & $61.41 \pm 2.55 \mathrm{a}$ & $64.59 \pm 2.27 \mathrm{a}$ & $57.76 \pm 5.72 b$ & $61.34 \pm 2.42 \mathrm{a}$ & $62.77 \pm 2.20 \mathrm{a}$ & 3.33 \\
\hline
\end{tabular}

${ }_{\mathrm{Z} V \mathrm{CV}}=\mathrm{CV}$ of each phenotypic index among cultivars $[\mathrm{cv}(\%)=100 \times \delta / \bar{x}]$.

${ }^{\mathrm{y}}$ Means within the same row denoted with different letters are significantly different at $P<0.05$ by Duncan's multiple range test.

Table 4. Methylation bands and levels in various pecan cultivars at four stages [inflorescence emergence, $30 \%$ of final fruit size, $70 \%$ of final fruit size, and fruit maturity].

\begin{tabular}{|c|c|c|c|c|c|c|c|c|c|c|}
\hline Cultivar & I (no.) & II (no.) & III (no.) & IV (no.) & $\begin{array}{l}\text { Methylation } \\
\text { bands (no.) }\end{array}$ & $\begin{array}{l}\text { Total } \\
\text { bands } \\
(\text { no. })^{z} \\
\end{array}$ & $\begin{array}{c}\text { Hemimethylation } \\
\text { level }(\%)\end{array}$ & $\begin{array}{c}\text { Full } \\
\text { methylation } \\
\text { level (\%) }\end{array}$ & $\begin{array}{c}\text { Hypermethylation } \\
\text { level }(\%)\end{array}$ & $\begin{array}{c}\text { Total } \\
\text { methylation } \\
\text { level }(\%)^{\mathrm{y}} \\
\end{array}$ \\
\hline Pawnee & 1,438 & 455 & 612 & 807 & 1,874 & 3,312 & 13.74 & 18.48 & 24.37 & 56.58 \\
\hline Stuart & 1,422 & 504 & 546 & 784 & 1,834 & 3,256 & 15.48 & 16.77 & 24.08 & 56.33 \\
\hline Kanza & 1,570 & 452 & 495 & 699 & 1,646 & 3,216 & 14.05 & 15.39 & 21.74 & 51.18 \\
\hline Shawnee & 1,504 & 463 & 552 & 709 & 1,724 & 3,228 & 14.34 & 17.10 & 21.96 & 53.41 \\
\hline Jinhua & 1,492 & 469 & 595 & 712 & 1,776 & 3,268 & 14.35 & 18.21 & 21.79 & 54.35 \\
\hline Seven cultivars ${ }^{\mathrm{x}}$ & 10,448 & 3,262 & 3,914 & 5,172 & 12,348 & 22,796 & 14.31 & 17.17 & 22.69 & 54.17 \\
\hline
\end{tabular}

${ }^{\mathrm{z}}$ Total amplified bands = I + II + III + IV; methylation bands = II + III + IV; I, II, III, and IV represent the number of bands for the methylation types unmethylation, hemimethylation, full methylation, and hypermethylation, respectively. Each value in the first six columns is the sum of the bands detected from the samples at four stages.

${ }^{\mathrm{y}}$ Total methylation level = (II + III + IV $) /(\mathrm{I}+\mathrm{II}+\mathrm{III}+\mathrm{IV})$; hemimethylation level = II/(I + II + III + IV $)$; full methylation level = III/(I + II + III + IV); and hypermethylation level = IV/(I + II + III + IV).

xIn the last row, labeled "seven cultivars," each value in the first six columns is the sum of the bands from the samples of the seven cultivars, and the levels in the last four columns are calculated based on the number of bands.

the hypermethylation level at the IE stage was the highest among the four stages, at $25.95 \%$, and the levels at the other stages were similar to each other, ranging from $18.70 \%$ to $19.68 \%$. Interestingly, based on the sum of the levels of these three methylation types, the variation in the total methylation level was generally similar to that in the full methylation level.

Methylation POLYMORPHisms AND SPECIFICITIES OF CCGG SITES AMONG PECAN CULTIVARS. For the samples collected at the IE, 30\%-FFS, 70\%-FFS, and FM stages, the polymorphism rates for the primers ranged from $75.22 \%$ (E6-H/M4) to $93.75 \%$ (E3-H/M1), from 69.70 (E1-H/M1) to 90.24 (E4-H/M2), from $59.18 \%(\mathrm{E} 1-\mathrm{H} / \mathrm{M} 1)$ to $89.92 \%(\mathrm{E} 2-\mathrm{H} / \mathrm{M} 2)$, and from $65.63 \%$ (E5-H/M3) to $92.59 \%$ (E3-H/M1), respectively (Fig. 2A). In addition, we defined the polymorphic sites of the four stages as the sites showing polymorphism among cultivars at any stage and quantified the polymorphism rate for each primer set. Compared with the polymorphism rate for each stage, the increased polymorphism rates of the four stages for each primer set ranged from 87.04\% (E5-H/M2) to 98.08\% (E1-H/M1). For high polymorphism, the eight primer sets were demonstrated to be suitable for studying DNA methylation in pecan. In addition, an average of $90,91,85$, or 85 polymorphic fragments among the cultivars were amplified by each primer set at the four stages. The polymorphism rates of the eight primer sets substantially decreased from the $30 \%$-FFS to $70 \%$-FFS stages and increased slightly at the FM stage, with rates of $82.29 \%, 81.73 \%, 78.64 \%$, and $79.09 \%$ being observed at the IE, 30\%-FFS, 70\%-FFS, and FM stages, respectively (Fig. 2A).

In total, 106, 98, 89, and 81 specific sites were detected among the seven pecan cultivars at the IE, 30\%-FFS, 70\%-FFS, and FM stages, with specific polymorphism rates of $13.17 \%$, $11.91 \%, 11.13 \%$, and $10.15 \%$, respectively. At the IE, $30 \%$-FFS, 70\%-FFS, and FM stages, the ratio of specific sites belonging to the cultivars ranged from $0.92 \%$ (Shawnee) to $3.47 \%$ (Caddo), $1.02 \%$ (Stuart) to $2.04 \%$ (Kanza), $1.05 \%$ (Stuart) to $2.31 \%$ (Mahan), and $0.70 \%$ (Mahan) to $2.11 \%$ (Pawnee), respectively (Fig. 2B). The detection of all specific sites showed that three sites presented specificity at all four stages (Table 5).

Changes in Methylation PATterns BetWeen STAGes fOR THE PECAN CULTIVARS. Based on the F-MSAP data from each cultivar at the four stages, methylation patterns belonging to two adjacent stages were compared, and six types were found: demethylation (DM), de novo methylation (DNM), nonmethylation state preservation (NMSP), changes in the pattern of the 

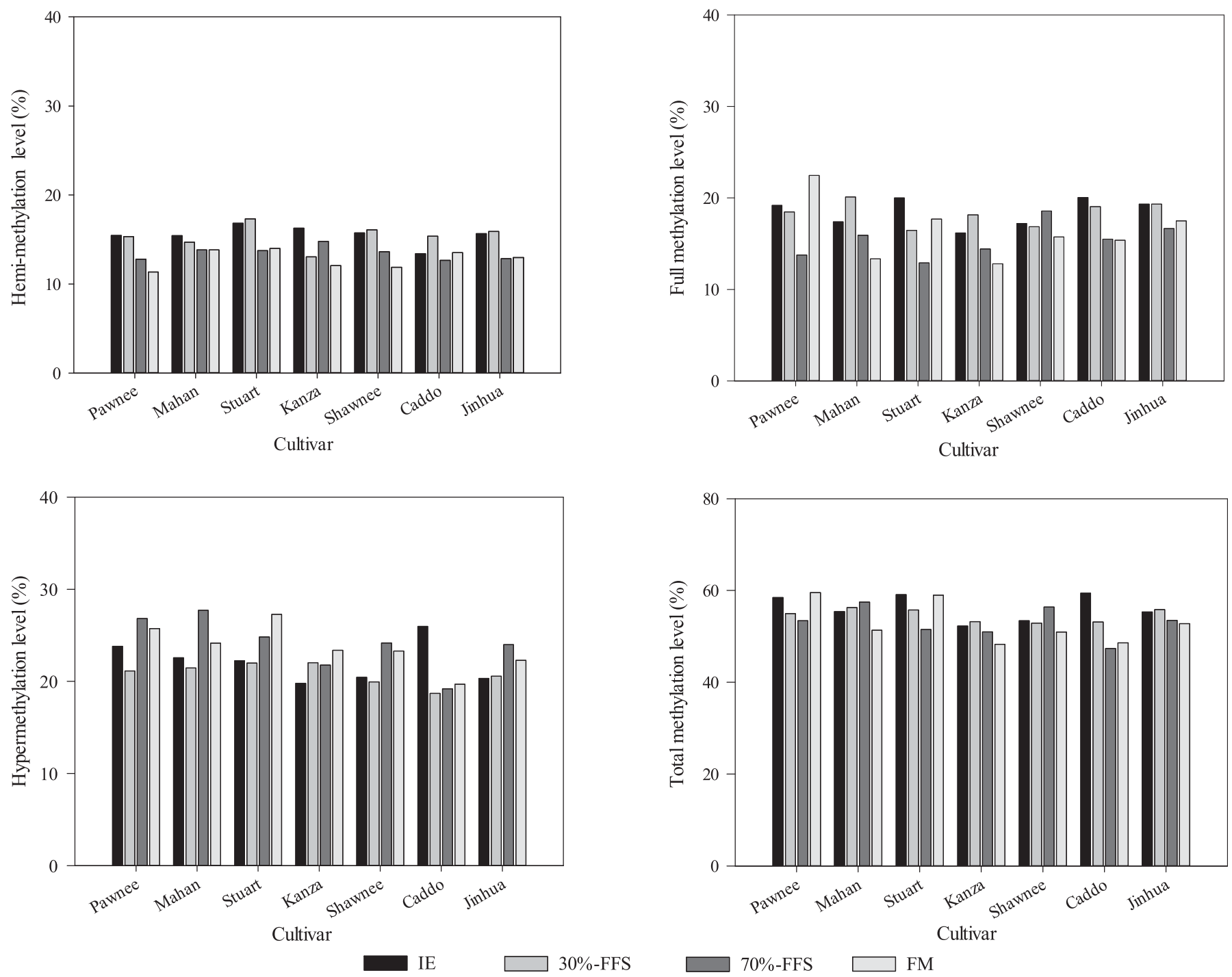

Fig. 1. Methylation levels of pecan cultivars among four stages are as follows: inflorescence emergence (IE), 30\% of final fruit size ( $30 \%$-FFS), $70 \%$ of final fruit size (70\%-FFS), and fruit maturity (FM). The total methylation level is the sum of the hemimethylation level, full methylation level, and hypermethylation level.

methylation state (CMS), no change in the pattern of the methylation state (NCMS), and methylation state preservation (MSP) (Fig. 3; Table 6). The results presented in Fig. 3 show that from the IE to $70 \%$-FFS stages, DM\%, DNM\%, and CMS $\%$ in the pecan cultivars increased and remained at higher levels at the $70 \%$-FFS stage, whereas a reverse trend appeared for $\mathrm{NMSP} \%, \mathrm{NCMS} \%$, and MSP\%. According to changes in the methylation patterns reflected by the DM, DNM, and CMS types, the methylation patterns changed at a larger proportion of CCGG sites from the 30\%-FFS to 70\%-FFS stages. Compared with the other types, the MSP\% of $36.65 \%$ to $47.36 \%$ was generally the highest among all cultivars at any stage, followed by NMSP $\%$, at $29.29 \%$ to $41.70 \%$.

Cluster analysis and PCoA of EPIGeNetic Relationships AMONG THE PECAN CULTIVARS. The Dice coefficients ranged from 0.698 to 0.778 among the seven pecan cultivars, with an average coefficient of 0.735 . The coefficient between 'Caddo' and 'Kanza' was the lowest, whereas that between 'Shawnee' and 'Jinhua' was the highest, which suggested that the most distant epigenetic relationship was between 'Caddo' and
'Kanza', and that the closest epigenetic relationship was between 'Shawnee' and 'Jinhua'. Based on the Dice coefficients, a dendrogram was constructed (Fig. 4), and good clustering results were obtained, as suggested by the matrix correlation $(r=0.876)$. The line corresponding to the coefficient axis with a scale value of 0.75 was treated as the clustering standard of the pecan cultivars. Based on the clustering figure, the seven cultivars were divided into four groups. Group I was composed of 'Pawnee' and 'Stuart'; group II comprised 'Mahan', 'Shawnee', and 'Jinhua'; group III comprised 'Caddo'; and group IV consisted of 'Kanza'.

The PCoA results showed the variance contribution rates of the previous three principal coordinates to be $19.6 \%, 19.0 \%$, and $18.2 \%$. We obtained two- and three-dimensional diagrams by sorting the seven cultivars based on the previous two and three principal coordinates, respectively (Fig. 5A and B). According to Fig. 5A, the seven pecan cultivars were classified into three groups when sorted based on the previous two principal coordinates, among which Caddo and Kanza were classified into groups of their own, and the other cultivars 
A

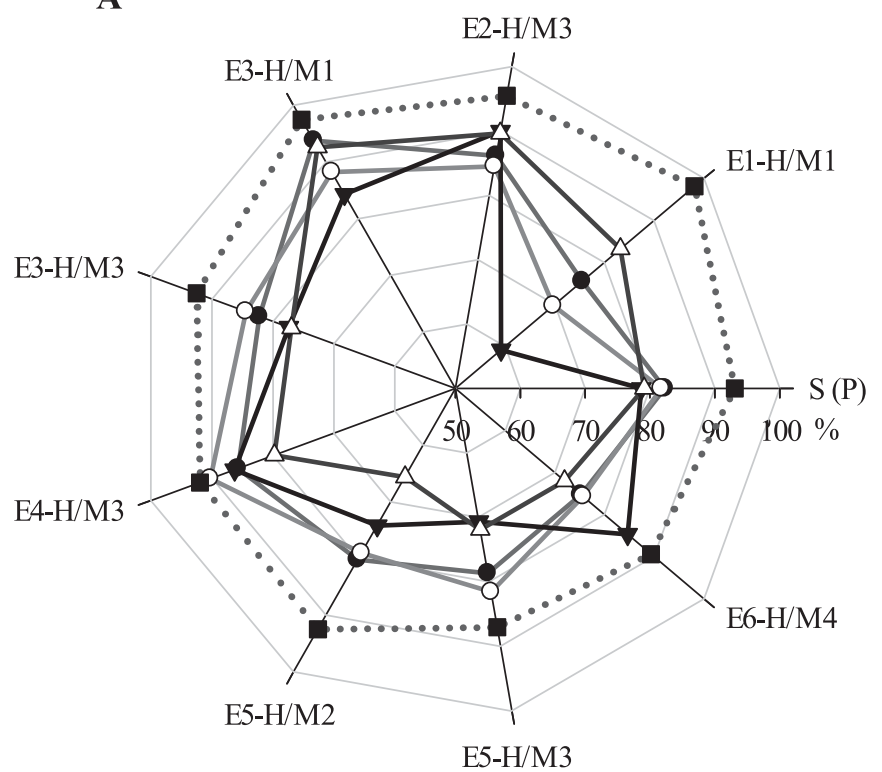

B

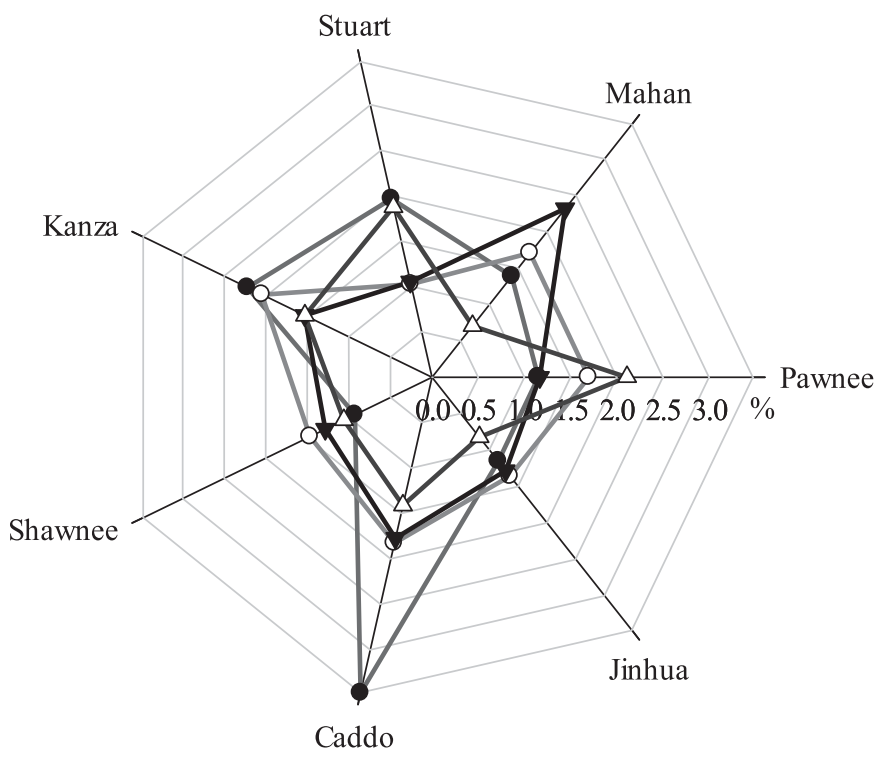

-... Four stages

Fig. 2. Variation in methylation patterns among the pecan cultivars across the four stages: inflorescence emergence (IE), $30 \%$ of final fruit size (30\%-FFS), $70 \%$ of final fruit size (70\%-FFS), and fruit maturity (FM). (A) The methylation polymorphism rates of the sites amplified by eight primer sets among seven pecan cultivars. The polymorphic sites are defined as the sites with different methylation patterns among the cultivars. The polymorphic sites of the four stages are defined as the sites showing polymorphism among cultivars at any stage, and the polymorphism rates of the four stages are indicated with a dotted line. $\mathrm{S}$ (P) represents the polymorphism rates of the eight primer sets. (B) The specific polymorphism rates of the sites detected among seven pecan cultivars. The specific sites are the sites at which the methylation pattern of a cultivar is different from that belonging to the other six cultivars, whereas the methylation patterns of the other six cultivars are the same.

Table 5. Specific sites possessed by the seven cultivars at all four stages: inflorescence emergence (IE), 30\% of final fruit size (30\%-FFS), $70 \%$ of final fruit size ( $70 \%$-FFS), and fruit maturity (FM). I, II, III, or IV in the same row represent the methylation patterns of seven cultivars in the same CCGG site [unmethylation (I), hemimethylation (II), full methylation (III), and hypermethylation (IV); the "IV" in bold formatting represents hypermethylation or no CCGG sequences]. The specific sites are the sites at which the methylation pattern of a cultivar is different from that belonging to the other six cultivars, whereas the methylation patterns of the other six cultivars are the same. Three specific sites were identified at which the methylation specificity remained stable in the four stages of the seven cultivars.

\begin{tabular}{|c|c|c|c|c|c|c|c|c|c|}
\hline Primers & Site & Stage & Pawnee & Mahan & Stuart & Kanza & Shawnee & Caddo & Jinhua \\
\hline E1-H/M1 & $369 \mathrm{bp}$ & Four stages & I & $\mathrm{I}$ & I & I & I & I & IV \\
\hline \multirow[t]{4}{*}{ E3-H/M3 } & $281 \mathrm{bp}$ & IE & I & I & I & I & I & III & I \\
\hline & & $30 \%$-FFS & I & I & I & I & I & IV & I \\
\hline & & $70 \%$-FFS & I & I & I & I & I & II & I \\
\hline & & FM & I & I & I & I & I & IV & I \\
\hline \multirow[t]{4}{*}{ E5-H/M2 } & $158 \mathrm{bp}$ & IE & I & I & I & I & I & II & I \\
\hline & & $30 \%$-FFS & I & I & I & III & I & I & I \\
\hline & & $70 \%$-FFS & II & IV & IV & IV & IV & IV & IV \\
\hline & & FM & IV & IV & III & IV & IV & IV & IV \\
\hline
\end{tabular}

comprised the third group. Based on the classification according to the previous two principal coordinates, further classification of the seven pecan cultivars was performed in the direction of the third principal coordinate (Fig. 5B). No changes in the classification of 'Caddo' and 'Kanza' were observed in the direction of the third principal coordinate, and the other five cultivars were classified into two groups: one group comprising Pawnee and Stuart and another comprising Mahan, Jinhua, and Shawnee. The PCoA results were consistent with those of the cluster analysis. However, the relationships among the cultivars could be revealed more intuitively in different directions and aspects using PCoA.

\section{Discussion}

In this study, the F-MSAP technique was applied to detect cytosine methylation in pecan for the first time and produced clear methylation profiles for the analysis of methylation in pecan cultivars at four stages (IE, 30\%-FFS, 70\%FFS, and FM). The total methylation levels ranged from $51.18 \%$ to $56.58 \%$ among the seven pecan cultivars, and the polymorphic sites accounted for $82.29 \%, 81.73 \%$, $78.64 \%$, and $79.09 \%$ of the sequences at the four stages, respectively, suggesting that variation in methylation existed among the pecan cultivars. Studies on various species in which the MSAP technique has been used have demonstrated that methylation levels are specific to different species, ranging from $4.08 \%$ to $48.3 \%$ for most plants investigated thus far (Baurens et al., 2004; Cervera et al., 2002; Hong and Deng, 2005; Li et al., 2002, 2014; Lu et al., 2008; Peraza-Echeverria et al., 2001; Xiong et al., 1999; Yang et al., 2011 ), and the levels are rarely higher than $50 \%$ for plants, as observed in maize [Zea mays (Candaele et al., 2014)]. The methylation levels recorded in the pecan cultivars were higher 

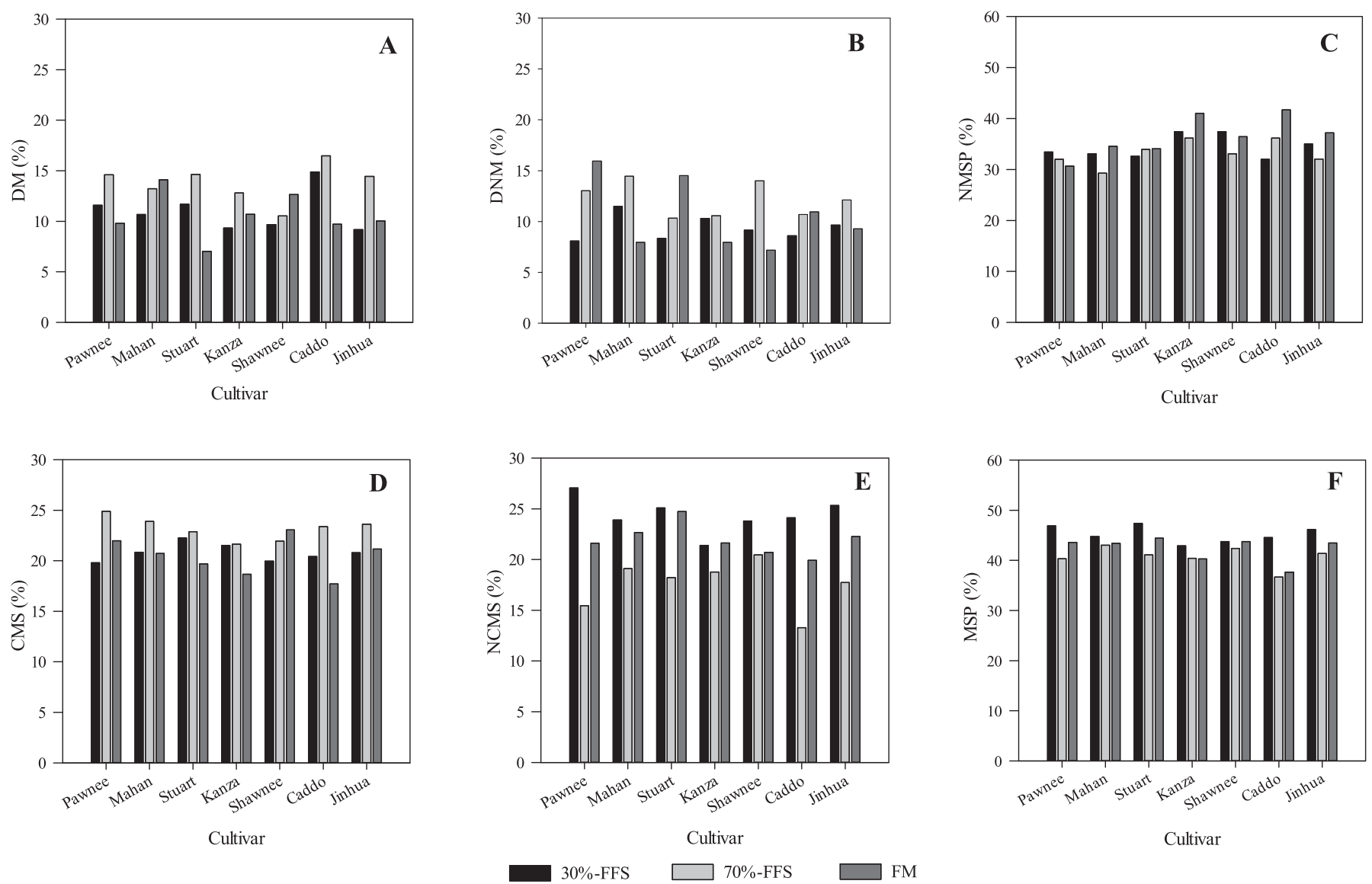

Fig. 3. Changes in the methylation patterns between stages for the seven pecan cultivars. The values represent the ratios of CCGG sites with altered methylation patterns compared with those at the same sites from the previous stage. $30 \%-\mathrm{FFS}=30 \%$ of final fruit size; $70 \%$-FFS $=70 \%$ of final fruit size; $\mathrm{FM}=$ fruit maturity; $\mathrm{DM}=$ demethylation; $\mathrm{DNM}=$ de novo methylation; NMSP = nonmethylation state preservation; $\mathrm{CMS}=$ changes in pattern of methylation state; $\mathrm{NCMS}=$ no change in pattern of methylation state; and MSP = methylation state preservation.

Table 6. Six types of changing methylation patterns determined by comparing adjacent stages of pecan cultivars.

\begin{tabular}{lll}
\hline No. & \multicolumn{1}{c}{ Type } & \multicolumn{1}{c}{ Changes in methylation patterns } \\
\hline DM & Demethylation & $\mathrm{II} \rightarrow \mathrm{I}, \mathrm{III} \rightarrow \mathrm{I}$, IV $\rightarrow$ I \\
DNM & De novo methylation & $\mathrm{I} \rightarrow \mathrm{II}, \mathrm{I} \rightarrow \mathrm{III}, \mathrm{I} \rightarrow \mathrm{IV}$ \\
NMSP & Nonmethylation state preservation & $\mathrm{I} \rightarrow \mathrm{I}$ \\
CMS & Changes in pattern of methylation state & $\mathrm{II} \rightarrow \mathrm{III}, \mathrm{II} \rightarrow \mathrm{IV}, \mathrm{III} \rightarrow \mathrm{II}, \mathrm{III} \rightarrow \mathrm{IV}$, IV $\rightarrow$ II, IV $\rightarrow$ III \\
NCMS & No change in pattern of methylation state & $\mathrm{II} \rightarrow \mathrm{II}, \mathrm{III} \rightarrow \mathrm{III}, \mathrm{IV} \rightarrow \mathrm{IV}$ \\
MSP & Methylation state preservation & Including the types of changes in CMS and NCMS
\end{tabular}

${ }_{\mathrm{Z}}^{\mathrm{I}}$, II, III, and IV represent the methylation types unmethylation, hemimethylation, full methylation and hypermethylation, respectively.

than those reported for most other species, indicating that methylation occurs extensively in pecan genomes. Unlike most MSAP analyses of other species, the incidence of type IV $(0,0)$ (confirmed as hypermethylation) was quantified and discussed in this study based on the existence of the site confirmed by the methylation status at other stages, which may have contributed to the high but more accurate methylation level obtained for pecan. Because MSAP allows the detection of methylation only at CCGG sequences, the results obtained using this technique might underestimate the level of genomic cytosine methylation, which was verified by the lower methylation level detected by the MSAP method in maize than that obtained by bisulfite sequencing (Candaele et al., 2014; Gent et al., 2013). In addition, this study revealed hypermethylation to be the dominant type among the four methylation types. Furthermore, the full methylation levels were higher than those of hemimethylation, which is consistent with the results obtained in other plants, such as maize (Candaele et al., 2014), sorghum [Sorghum bicolor (Zhang et al., 2011)], and rice (Wang et al., 2011).

According to reports on other molecular markers, such as RAPD, SSR, and ISSR markers, performed in pecan cultivars, about four to nine polymorphic fragments are amplified by each primer combination (Jia et al., 2011; Kaur et al., 2016; Li et al., 2015). However, in this study, an average of $90,91,85$, and 85 polymorphic fragments were amplified at the IE, 30\%-FFS, $70 \%$-FFS, and FM stages, respectively, by each primer set among the cultivars with sufficient polymorphism rates, demonstrating that methylation polymorphisms occur more frequently than do 
DNA sequence polymorphisms in pecan cultivars, which is consistent with reports from tobacco (Yang et al., 2011) and Clementine mandarin (Fang et al., 2008). Importantly, previous studies have also suggested that the different phenotypes observed among cultivars may be regulated by variations in methylation patterns (Fang et al., 2008; Yang et al., 2011). Furthermore, a study in Clivia miniata showed that leaf patterns (yellow, green, and striped) might be caused by differential DNA methylation at CCGG sites (Wang et al., 2015). Herein, nine phenotypic indices of leaflets collected from seven pecan cultivars in July were investigated, and significant differences $(P<0.05)$ were observed in each of these indices among the cultivars except for leaflet length and perimeter. Therefore, we

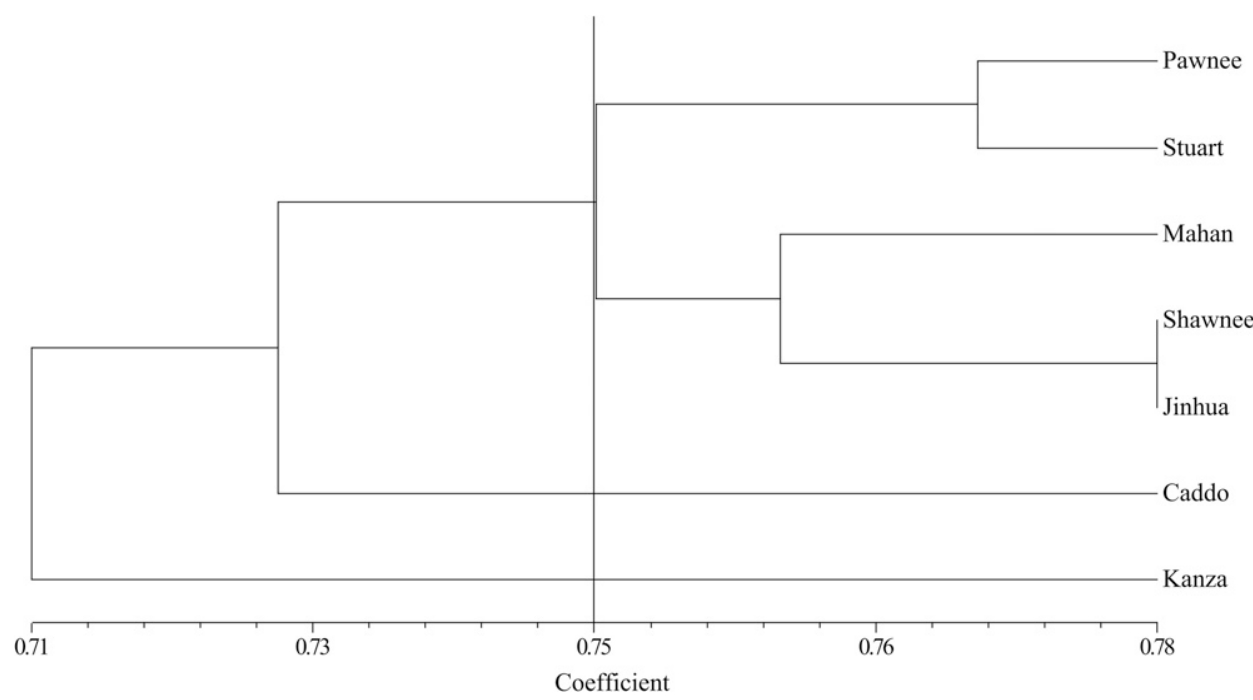

Fig. 4. Dendrogram of the seven pecan cultivars established using Dice coefficients based on the methylation patterns. The matrix correlation $(r)$ obtained from the cophenetic correlation analysis $=0.876$. The line corresponding to the coefficient axis with a scale value of 0.75 was obtained by the NTSYS software automatically and was treated as the clustering standard of the pecan cultivars. speculate that cytosine methylation may be an important factor in the induction of phenotypic variation in leaves. Through cluster analysis and PCoA of the observed methylation patterns, the first epigenetic dendrogram and diagrams of PCoA for pecan cultivars were built. According to the dendrogram and diagrams of PCoA, 'Kanza' and 'Caddo' were classified into groups of their own, whereas the other five cultivars were separated from these two cultivars but were also classified into two groups: one group comprising Pawnee and Stuart and another comprising Mahan, Jinhua, and Shawnee. Based on the previously reported lineage of pecan cultivars (Conner and Wood, 2001; Grauke, 2004; Grauke et al., 2015), Pawnee, Stuart, Mahan, Shawnee, and Jinhua are descending from Schley [Schley is the parent of Shawnee, and it may be the parent of Mahan and a sibling of Stuart; Jinhua may be a Mahan descendant; Pawnee originated by controlled cross (Mohawk $\times$ Starking Hardy Giant) and Mohawk originated by controlled cross (Success $\times$ Mahan)], whereas Kanza and Caddo do not connect back to Schley. The epigenetic relationships that we found are generally consistent with the lineage of pecan cultivars, but the separation of the five cultivars (Pawnee, Stuart, Mahan, Shawnee, and Jinhua) demonstrates divergence between these two relationships, which is supported by a report on cotton genotypes (Osabe et al., 2014). These studies have revealed complex relationships between epigenetic and genetic structure, which need to be explained with more evidences in the further research.
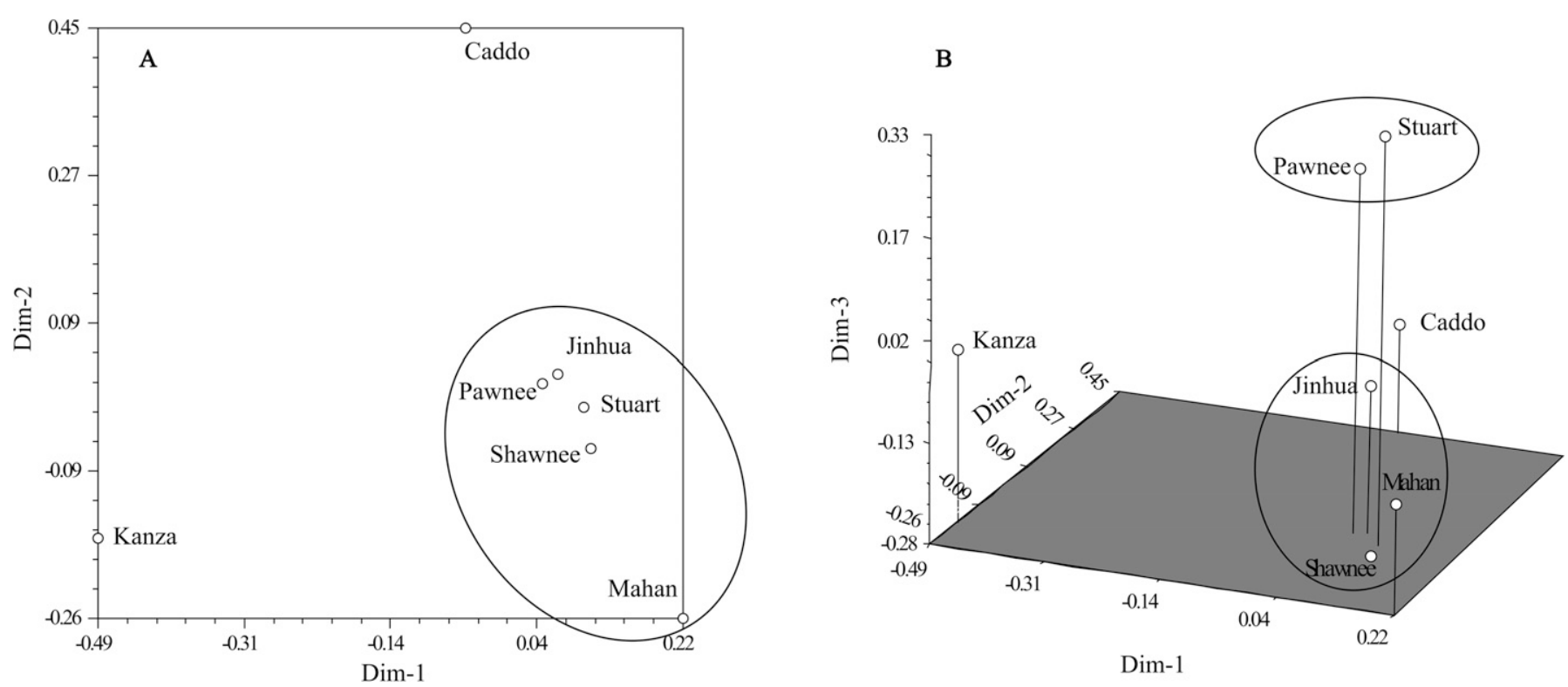

Fig. 5. Principal coordinate analysis (PCoA) of the seven pecan cultivars based on the methylation patterns. (A) Two-dimensional diagram of the previous two principal coordinates from PCoA in the seven pecan cultivars. (B) Three-dimensional diagram of the previous three principal coordinates from PCoA in the seven pecan cultivars. 
Cytosine methylation is important for plant development and changes with plant growth and development, as shown by reports on A. thaliana (Finnegan et al., 1998; Ruiz-García et al., 2005), rice (Xiong et al., 1999), and tobacco (Zhang et al., 2015a). In this study, obvious decreases in methylation levels, polymorphism rates, and specific polymorphism rates were observed in the pecan cultivars from the $30 \%$-FFS to $70 \%$-FFS stages. In addition, to trace changes in methylation patterns between the different stages, we creatively classified the changing patterns into six types, including DM, DNM, NMSP, CMS, NCMS, and MSP (Table 6). From the IE to $70 \%$-FFS stages, DM\%, DNM\%, and CMS\%, which reflected changes in methylation patterns, increased and remained at higher levels at the $70 \%$-FFS stage. This finding demonstrated that methylation patterns change over a greater range of CCGG sites from the $30 \%$-FFS to $70 \%$-FFS stages, which decreases methylation levels, polymorphism rates, and specific polymorphism rates. At the $70 \%$-FFS stage, pecan trees remain at the vigorously growing stage, and their leaves are generally the most mature at this stage. Changes in DNA methylation have been shown to be correlated with changes in gene expression in a tissue-specific or developmentally regulated manner (Jost and Saluz, 1995). Therefore, the growth characteristics of pecan trees in this period may be regulated by drastic changes in the methylation status of CCGG sites.

In the examination of such plentiful polymorphism data, it appears to be important to locate the key sequences regulating important traits, which can lay a good foundation for the breeding of exceptional cultivars with molecular tools. In this study, the measured phenotypic traits were mainly used to demonstrate the variation in the leaves among the pecan cultivars and cannot be correlated with the differential markers due to a lack of sample data. It is worth mentioning that three specific sites were detected at which the methylation specificity for the seven pecan cultivars was stably maintained at the four stages. These specific sites may play important roles in phenotypic trait determination. To reveal the mechanisms underlying this regulation, further research is needed to analyze the functions of differential fragments through collecting bands from polyacrylamide gels, cloning, sequencing, and blasting against the GenBank database. As a powerful tool for the sensitive detection of methylation status, the F-MSAP technique presents potential for use in the identification of cultivars. In this study, it was not difficult to identify the seven pecan cultivars based on the obtained polymorphic bands. However, factors such as developmental stages, age, and environmental factors may change the methylation status at some methylated sites. Therefore, to identify pecan cultivars effectively, it appears necessary to study the methylation status of pecan cultivars under different conditions and to identify polymorphic sites that present stable methylation patterns.

In this study, the leaves collected as the research object were subjected to F-MSAP analysis. Notably, pecans are an important nut crop; thus, there are many important areas of research, especially regarding insect resistance and the improvement of nut quality and yield. Therefore, studies on DNA methylation will be developed extensively in pecan and become a new strategy for addressing important scientific problems in pecan.

\section{Literature Cited}

Andersen, P.C. 2015. The pecan tree. 14 Mar. 2018. <http://edis.ifas. ufl.edu/pdffiles/HS/HS22900.pdf>.

Baurens, F.C., J. Nicolleau, T. Legavre, J.L. Verdeil, and O. Monteuuis. 2004. Genomic DNA methylation of juvenile and mature Acacia mangium micropropagated in vitro with reference to leaf morphology as a phase change marker. Tree Physiol. 24:401-407.

Bednarek, P.T., R. Orłowska, and A. Niedziela. 2017. A relative quantitative methylation-sensitive amplified polymorphism (MSAP) method for the analysis of abiotic stress. BMC Plant Biol. 17:79.

Candaele, J., K. Demuynck, D. Mosoti, G.T.S. Beemster, D. Inzé, and H. Nelissen. 2014. Differential methylation during maize leaf growth targets developmentally regulated genes. Plant Physiol. 164:13501364.

Cervera, M.T., L. Ruiz-García, and J.M. Martínez-Zapater. 2002. Analysis of DNA methylation in Arabidopsis thaliana based on methylation-sensitive AFLP markers. Mol. Genet. Genomics 268:543-552.

Conner, P.J. and B.W. Wood. 2001. Identification of pecan cultivars and their genetic relatedness as determined by randomly amplified polymorphic DNA analysis. J. Amer. Soc. Hort. Sci. 126:474-480.

Fang, J., C. Song, Y. Zheng, Y. Qiao, Z. Zhang, Q. Dong, and C.T. Chao. 2008. Variation in cytosine methylation in Clementine mandarin cultivars. J. Hort. Sci. Biotechnol. 83:833-839.

Fang, J.G., C.N. Song, J.L. Qian, X.Y. Zhang, L.F. Shangguan, H.P. $\mathrm{Yu}$, and X.C. Wang. 2010. Variation of cytosine methylation in 57 sweet orange cultivars. Acta Physiol. Plant. 32:1023-1030.

Finnegan, E.J., R.K. Genger, W.J. Peacock, and E.S. Dennis. 1998. DNA methylation in plants. Annu. Rev. Plant Physiol. Plant Mol. Biol. 49:223-247.

Finnegan, E.J., W.J. Peacock, and E.S. Dennis. 1996. Reduced DNA methylation in Arabidopsis thaliana results in abnormal plant development. Proc. Natl. Acad. Sci. USA 93:8449-8454.

Fraga, M.F., R. Rodríguez, and M.J. Cañal. 2002. Genomic DNA methylation-demethylation during aging and reinvigoration of Pinus radiata. Tree Physiol. 22:813-816.

Fulneček, J. and A. Kovařík. 2014. How to interpret methylation sensitive amplified polymorphism (MSAP) profiles? BMC Genet. 15:2.

Gent, J.I., N.A. Ellis, L. Guo, A.E. Harkess, Y.Y. Yao, X.Y. Zhang, and R.K. Dawe. 2013. CHH islands: De novo DNA methylation in near-gene chromatin regulation in maize. Genome Res. 23:628.

Gonzalgo, M.L. and P.A. Jones. 1997. Mutagenic and epigenetic effects of DNA methylation. Mutat. Res. 386:107-118.

Grauke, L.J. 2004. Yunnan pecans. 18 Apr. 2018. <https://cgru.usda. gov/carya/cgc/Yunnan\%20Pecans.pdf>.

Grauke, L.J., M.J. Iqbal, A.S. Reddy, and T.E. Thompson. 2003. Developing microsatellite DNA markers in pecan. J. Amer. Soc. Hort. Sci. 128:374-380.

Grauke, L.J., R. Klein, M.A. Grusak, and P. Klein. 2015. The forest and the trees: Applications for molecular markers in the repository and pecan breeding program. Acta Hort. 1070:109-126.

Han, M., F. Peng, and P. Marshall. 2018. Pecan phenology in southeastern china. Ann. Appl. Biol. 172:1-10.

Hong, L. and X. Deng. 2005. Analysis of DNA methylation in navel oranges based on MSAP marker. Scientia Agr. Sinica 38:2301-2307.

Jia, X.D., T. Wang, M. Zhai, Y.R. Li, and Z.R. Guo. 2011. Genetic diversity and identification of Chinese-grown pecan using ISSR and SSR markers. Molecules 16:10078-10092.

Jost, J.P. and H.P. Saluz. 1995. DNA methylation: Molecular biology and biological significance. Qrtly. Rev. Biol. 64:425-451.

Kaur, R., E. Bhardwaj, S. Shilpa, K. Kumar, D. Singh, and D. Sharma. 2016. Characterization of pecan (Carya illinoensis) genotypes using RAPD markers. Intl. J. Farm Sci. 6:77-81.

Li, H., R. Zhang, F.R. Peng, Y.R. Li, and M. Zhai. 2015. Genetic diversity and identification of pecan by ISSR markers. J. Nanjing For. Univ. Natural Sci. Ed. 4:7-12.

Li, J.H., S.Y. Xing, Q. Zhang, P.J. Yao, and C.C. Wang. 2014. The changes in DNA methylation levels and patterns of Ginkgo biloba var. epiphylla. Acta Hort. Sinica 41:1535-1544.

Li, X., M. Xu, and S.S. Korban. 2002. DNA methylation profiles differ between field- and in vitro -grown leaves of apple. J. Plant Physiol. 159:1229-1234. 
Lira-Medeiros, C.F., C. Parisod, R.A. Fernandes, C.S. Mata, M.A. Cardoso, and P.C. Gomes Ferreira. 2010. Epigenetic variation in mangrove plants occurring in contrasting natural environment. PLoS One 5:e10326.

Lu, Y., T. Rong, and M. Cao. 2008. Analysis of DNA methylation in different maize tissues. J. Genet. Genomics 35:41-48.

Movahedi, A., W.B. Sun, J.X. Zhang, X.L. Wu, M. Mousavi, K. Mohammadi, T.M. Yin, and Q. Zhuge. 2015. RNA-directed DNA methylation in plants. Plant Cell Rpt. 34:1857-1862.

Nakano, Y., N. Steward, M. Sekine, T. Kusano, and H. Sano. 2000. A tobacco NtMET1 cDNA encoding a DNA methyltransferase: Molecular characterization and abnormal phenotypes of transgenic tobacco plants. Plant Cell Physiol. 41:448-457.

Osabe, K., J.D. Clement, F. Bedon, F.A. Pettolino, L. Ziolkowski, D.J. Llewellyn, E.J. Finnegan, and I.W. Wilson. 2014. Genetic and DNA methylation changes in cotton (Gossypium) genotypes and tissues. PLoS One 9:e86049.

Peraza-Echeverria, S., V.A. Herrera-Valencia, and A. Kay. 2001. Detection of DNA methylation changes in micropropagated banana plants using methylation-sensitive amplification polymorphism (MSAP). Plant Sci. 161:359-367.

Reyna-López, G.E., J. Simpson, and J. Ruiz-herrera. 1997. Differences in DNA methylation patterns are detectable during the dimorphic transition of fungi by amplification of restriction polymorphisms. Mol. Genet. Genomics 253:703-710.

Ruiz-García, L., M.T. Cervera, and J.M. Martínez-Zapater. 2005. DNA methylation increases throughout Arabidopsis development. Planta 222:301-306.

Sambrook, J. and D.W. Russell. 2001. Molecular cloning: A laboratory manual. 3rd ed. Cold Spring Harbor Lab. Press, Long Island, NY.

Wang, Q.M., L. Wang, Y.B. Zhou, J.G. Cui, Y.Z. Wang, and C.M. Zhao. 2015. Leaf patterning of Clivia miniata var. variegata is associated with differential DNA methylation. Plant Cell Rpt. 35:167-184.

Wang, W.S., Y.J. Pan, X.Q. Zhao, D. Dwivedi, L.H. Zhu, J. Ali, B.Y. Fu, and Z.K. Li. 2011. Drought-induced site-specific DNA methylation and its association with drought tolerance in rice (Oryza sativa L.). J. Expt. Bot. 62:1951-1960.

Wood, B.W., J.A. Payne, and L.J. Grauke. 1990. The rise of the U.S. pecan industry. HortScience 594:721-723.

Xiong, L.Z., C.G. Xu, M.A. Saghai Maroof, and Q.F. Zhang. 1999. Patterns of cytosine methylation in an elite rice hybrid and its parental lines, detected by a methylation-sensitive amplification polymorphism technique. Mol. Gen. Genet. 261:439-446.

Xu, Q., D. Sun, and Y. Zhang. 2005. F-MSAP: A practical system to detect methylation in chicken genome. Chin. Sci. Bul. 50:20392044.

Yang, C., Y. Huang, Z. Tang, L. Lu, and L. Liu. 2011. Analysis of DNA methylation variation in sibling tobacco (Nicotiana tabacum) cultivars. Afr. J. Biotechnol. 10:874-881.

Zhang, M., J.N. Kimatu, K. Xu, and B. Liu. 2010. DNA cytosine methylation in plant development. J. Genet. Genomics 37:1-12.

Zhang, M., C. Xu, W.D. Von, and B. Liu. 2011. Tissue-specific differences in cytosine methylation and their association with differential gene expression in sorghum. Plant Physiol. 156:19551966.

Zhang, P.Y., J.G. Wang, Y.P. Geng, J.R. Dai, Y. Zhong, Z.Z. Chen, K. Zhu, X.Z. Wang, and S.Y. Chen. 2015a. MSAP-based analysis of DNA methylation diversity in tobacco exposed to different environments and at different development phases. Biochem. Syst. Ecol. 62:249-260.

Zhang, R., F. Peng, and Y. Li. 2015b. Pecan production in China. Scientia Hort. 197:719-727.

Zhang, R., F. Peng, Y. Liang, M. Hao, and Y. Li. 2015c. Flowering and pollination characteristics of Chinese-grown pecan (Carya illinoinensis). Acta Hort. 1070:43-51.

Zhao, Y., M.Y. Chen, K.B. Storey, L.N. Sun, and H.S. Yang. 2015. DNA methylation levels analysis in four tissues of sea cucumber Apostichopus japonicus based on fluorescence-labeled methylationsensitive amplified polymorphism (F-MSAP) during aestivation. Comp. Biochem. Physiol. Part B Biochem. Mol. Biol. 181:26-32. 